\title{
Formación para la inclusión social: Menciones y optativas en la titulación de Educaçao Social en Portugal. Estudio comparado
}

\author{
Viana-Orta, María-Isabel \\ Universitat de València, Valencia, España \\ M.Isabel.Viana@uv.es \\ Camacho, George \\ Instituto Politécnico de Santarém, Santarém, Portugal \\ george.camacho@ese.ipsantarem.pt \\ Senent, Joan María \\ Universitat de València, Valencia, España \\ Joan.M.Senent@uv.es
}

\section{Resumen}

Una de las figuras profesionales que trabaja para la eliminación de cualquier tipo de exclusión, tanto de personas como de colectivos, es la de educadora o educador social, se trata de una profesión reciente y con una formación también muy reciente sobre todo en los países del sur de Europa. En Portugal, por ejemplo, aparece por primera vez en 1989 y se extiende durante los primeros años 90. En estos países, con Servicios Sociales menos desarrollados que en el resto de Europa, se forma una figura polivante y poco especializada que pueda intervenir en diversos ámbitos y que deberá ir especializándose después a medida que trabaja (Senent, 2011). Actualmente, tras el proceso de convergencia europea, en Portugal la formación se concreta en dos ciclos: el primero, de 3 años académicos y 180 créditos ECTS, licenciatura; y el segundo, de 2 años académicos y 120 créditos ECTS, mestrado (master). La especialización se consigue por varios caminos: a través de la diversidad formativa existente en el primer ciclo (Animaçao Sociocultural; Animaçao Cultural e Educaçao Comunitaria; Animaçao e Intervençao Socioeducativa; Educaçao Social...); a través de las optativas y las prácticas en este primer ciclo; y cursando el segundo ciclo (mestrado). Centrándose en el primer ciclo y en la optatividad de la licenciatura de Educaçao Social, se presenta un estudio comparativo de todos los centros públicos que imparten esta titulación en Portugal, cuyas variables comparadas han sido: la existencia o no de menciones al título; el total de créditos de optativas; el número de créditos por optativa; la distribución de las materias optativas a lo largo de los diferentes cursos; y el total de optativas que se ofertan por centro. Se concluye con diferencias muy significativas de unos centros a otros, sobre todo en cuanto al total de créditos optativos que oscilan entre 0 y 26 , y con la dificultad de conocer en algunos casos las optativas ofrecidas.

\section{Abstract}

One of the professional working for the elimination of any type of exclusion, both individuals and groups, is the social educator, is a recent profession and also recently trained mostly in countries in the South of Europe. In Portugal, for example, appears for the first time in 1989 and during the early 1990s. In these countries, with less developed social services than in the reest of Europe, is a figure not specialized enough that it may professionaly envolved in various fields and it must go specializing later as he works (Senent, 2011). Currently, after the process of European convergence, in Portugal the training focuses on two clycles: the first, with 3 academic years and 180 ECTS credits, Bachelor's degree; and the second, with 2 academic years and 120 ECTS, mestrado (master's degree). Specialization is achieved by several ways: trough training in the first cycle (Animaçao Sociocultural; Animaçao Cultural e Educaçao Comunitaria; Animaçao e Intervençao Socioeducativa; Educaçao Social...); trough the optional subjets and practices in this first cycle; and completing the second cycle (mestrado). Focusing in the first cycle and de optional subject of the Social Education degreee, presents a comparative study of all public higher educations centres that teach this degree in Portugal, whose comparative variables have been: the existence or not of mentions to the title; the total credits of optional subjects; the total number of optional subjects offered by center; and the distribution of the optional subjets throughout the different levels. It concludes with very significant differences specially in terms of the total number of credits of optional subjects, ranging between 0 and 26 , and the difficulty of knowing the optional subjects offered in some cases.

Palabras clave: Educación Social, Formación en Educación Social, Educación Comparada, Educación Superior.

Keywords: Social Education, Social Education Training, Comparative Education, Higher Education. 


\section{INTRODUCCIÓN}

En el panorama europeo coexisten diferentes modelos de formación de educadores y educadoras sociales que, desde realidades diferentes presentan algunas características comunes. Portugal se ubica en el modelo meridional o mediterráneo junto con otros países del sur del continente, como Grecia, Italia y España, que tienen como primera característica común el hecho de que la formación es relativamente reciente, de los últimos veinte o treinta años dependiendo de países, y que su adscripción a la educación superior, sea en la vertiente politécnica o en la universidad, es todavía más reciente, datando de los últimos quince o veinte años en algunos de estos países del sur europeo (Senent, 1994; Senent, 2011).

En el caso de Portugal, la formación de los educadores y las educadoras sociales en el marco de la Educación Superior, comenzó en 1989 con la creación de la diplomatura con una duración de tres años (bacharelato) en el Instituto Superior de Ciências Educativas (ISCE) (Leitão, 2013) y en 1993 y 1994 en las Escuelas Superiores de Educación de los Institutos Politécnicos de Oporto y Santarém, respectivamente (Timóteo, 2013).

En 2001, se produjo una primera reorganización de la formación y se creó la licenciatura (Portaria n. ${ }^{\circ} 1068 / 2001$ ), con un plan de estudios organizado en dos etapas: una primera etapa de tres años (grau de bacharel) más un cuarto año (grau de licenciado), incrementándose así tanto las vertientes formativa e investigadora como la vertiente de intervención socioeducativa y aumentando, a su vez, el enfoque teórico en algunas áreas (Lietão, 2013).

En el curso 2006-2007 se produjo la adaptación al proceso de Bolonia y a la creación del Espacio Europeo de Educación Superior (EEES) que permitió, por un lado, unificar la denominación que era diferente en cada región del país (Oporto, Santarém y Algarve) y, por otro, armonizar sus planes de estudio. Siguiendo las orientaciones del Ministério da Ciência, Tecnologia e Ensino Superior (Decreto-Ley 74/2006 de 24 de marzo), los estudios de educación social pasaron a estar organizados en dos ciclos: el primer ciclo formado por 6 semestres (180 créditos) para obtener el grado de licenciatura y un segundo ciclo organizado en 4 semestres (120 créditos) para obtener el grado de mestre (master) (Leitão, 2013).

Pero más allá de todas estas reformas y cambios en la organización y estructura de la formación, un problema que perdura a lo largo de los años y que se extiende a toda la Educación Superior portuguesa, es la enorme dispersión de oferta formativa que existe. En ocasiones, la misma designación se relaciona con perfiles de formación diferentes pero también ocurre que designaciones diferentes se corresponden con perfiles muy próximos (Rocha y Camacho, 2009; Teixeira, 2014). Así, en el caso de la Educación Social, junto a la licenciatura de Educaçao Social, encontramos las licenciaturas de Animaçao Cultural; Animaçao Cultural e Educação Comunitaria; Animaçao Sociocultural; Animaçao Socioeducativa, entre otras.

Partiendo de esta gran diversificación de titulaciones, el objetivo del presente estudio es centrarse en la titulación de Educaçao Social para analizar el nivel de especialización que reciben estas y estos profesionales en su formación inicial a través de las menciones y de los créditos optativos.

\section{METODOLOGÍA}

Se presenta un estudio comparado que, partiendo del método comparativo de carácter deductivo propuesto inicialmente por Hilker y Bereday, ha recibido desde entonces aportaciones de diferentes comparatistas (Caballero, A., Manso, J., Matarranz, M., \& Valle, J.M., 2016; García Garrido, 1990; Ferrer, 2002; Martínez Usarralde, 2003 y 2006). Las cuatro etapas fundamentales del método son la fase descriptiva, la fase interpretativa, la fase de yuxtaposición y la fase comparativa propiamente dicha. Por cuestiones de espacio, se presenta aquí solo la última fase, la comparativa propiamente dicha o de conclusiones comparativas.

Las unidades comparativas han sido los planes de estudio de todos los centros públicos portugueses que han impartido la licenciatura de Educaçao Social durante el curso 2015-2016 (año en el que se inicia una investigación más amplia a nivel europeo todavía en curso), siendo un total de 6 centros ( $\mathrm{N}=6)$.

Las variables comparadas han sido: la existencia o no de menciones al título; el total de créditos de optativas; el número de créditos por optativa; la distribución de las materias optativas a lo largo de los diferentes cursos; y el total de optativas que se ofertan por centro. 
Tabla 1. Menciones y optatividad.

\begin{tabular}{|c|c|c|c|c|c|c|c|c|}
\hline \multirow{3}{*}{$\begin{array}{c}\text { Centro } \\
\text { (por orden alfabético) }\end{array}$} & \multirow{3}{*}{$\begin{array}{l}\text { Mención } \\
\text { (Sí / NO) }\end{array}$} & \multirow{2}{*}{\multicolumn{2}{|c|}{ Total Optatividad }} & \multicolumn{5}{|c|}{ Total optativ. ofertadas } \\
\hline & & & & \multirow[b]{2}{*}{$\begin{array}{c}\text { Crédito por } \\
\text { optativa }\end{array}$} & \multicolumn{3}{|c|}{ Distribución por cursos } & \multirow[b]{2}{*}{$\begin{array}{l}\text { Total } \\
\text { optativ. } \\
\text { ofertadas }\end{array}$} \\
\hline & & $\begin{array}{l}\text { Total } \\
\text { créditos } \\
\text { optativos }\end{array}$ & $\begin{array}{l}\% \text { respecto } \\
\text { al total de } \\
\text { créditos de la } \\
\text { titulación (180) }\end{array}$ & & $1^{\circ}$ & $2^{\circ}$ & $3^{\circ}$ & \\
\hline $\begin{array}{c}\text { Instituto Politécnico de } \\
\text { Bragança (Escola Superior } \\
\text { de Educaçao) }\end{array}$ & NO & 0 & - & - & - & - & - & - \\
\hline $\begin{array}{l}\text { Instituo Politécnico de } \\
\text { Leiria (Escola Superior de } \\
\text { Educaçao e } \\
\text { Ciências Sociais) }\end{array}$ & NO & 10 & $5 ’ 55 \%$ & 5 & 1 & - & 1 & 2 \\
\hline $\begin{array}{l}\text { Instituto Politécnico de } \\
\text { Oporto (Escola } \\
\text { Superior de Educaçao) }\end{array}$ & NO & 24 & $13 ’ 33 \%$ & 4 & 2 & 2 & 2 & 18 \\
\hline $\begin{array}{l}\text { Universidade do Algarve } \\
\text { (Escola Superior de Edu- } \\
\text { caçao e Comunicaçao) }\end{array}$ & NO & 26 & $14 ' 44 \%$ & $4 / 5$ & 2 & 3 & 1 & $?$ \\
\hline
\end{tabular}

Fuente: Elaboración propia.

En primer lugar, en relación a la existencia o no de menciones al título, como se puede observar en la Tabla 1, ningún centro las ofrece en sus planes de estudio.

En segundo lugar, en relación al total de créditos optativos ofrecidos, se puede observar que, en dos de los centros no se ofrecen créditos optativos y que, en el resto de casos (4 centros), el número máximo de créditos optativos ofrecidos es de 26 , lo que implica un 14 ' $44 \%$ del total de créditos de la titulación (180).

En tercer lugar, en relación al número de créditos por optativa, se puede observar también que la oscilación es mínima, variando solo de 4 a 5 créditos.

En cuarto lugar, en relación a la distribución de optativas a lo largo de los diferentes cursos, se puede observar también una gran diversidad. De los 4 centros que ofrecen créditos opativos, 2 centros los ofrecen en todos los cursos, $1^{\circ}, 2^{\circ}$ y $3^{\circ}$; otro centro, los ofrece en $1^{\circ}$ y en $3^{\circ}$ curso, y un último centro, los ofrece solo en $3^{\circ}$ curso.

En quinto y último lugar, en relación al número de optativas que se ofertan por centro, la diversidad de situaciones que se observa es todavía mayor. De los 4 centros, en dos no se pudo averiguar a través de sus páginas web cuáles eran las optativas que se ofrecían; en otro de los centros se ofrecían 18 optativas de las que, en total, había que cursar 6; y en el cuarto centro, solo se ofrecían 2 de un total de 2 que había que cursar, por lo que tampoco son verdaderas optativas para el alumnado, sino materias que van rotando, activándose y desactivándose cada curso.

Por todo ello, se puede concluir, que en Portugal, existe una gran diversidad en la formación de los y las profesionales de la intervención socioeducativa, con un buen número de titulaciones diferentes (Animaçao Cultural, Animaçao Cultural e Educaçao Comunitaria, Animaçao Sociocultural, Animaçao Socioeducativa...), pero que, centrando el análisis en la licenciatura de Educaçao 
Social, no existe una gran especialización: no existen menciones al título en ninguno de los centros; no todos los centros ofrecen optativas; y no todas las optativas que se ofrecen, son verdaderas optativas para el alumnado.

Por tanto, la especialización de estos profesionales en su formación incial en el caso de Portugal, se produce por la gran diversidad de titulaciones de primer ciclo (licenciaturas) relacionadas con la intervención socioeducativa existentes, y por la diversidad también de estudios de segundo ciclo (postgrado).

Este estudio presenta muchas limitaciones que marcan a su vez el camino a seguir en futuras investigaciones. En este sentido, sería interesante ampliar el estudio también a los centros privados; hacer un análisis comparado en profundidad de los planes de estudio de la licenciatura de Educaçao Social de los diferentes centros para analizar si la formación que reciben estos profesionales se asemeja en algún aspecto y tiene elementos comunes o si se trata de diferentes formaciones bajo el mismo nombre; analizar de forma comparada el resto de titulaciones para observar puntos en común entre ellas y puntos de divergencia; y seguir ampliando estos estudios a otros países europeos.

\section{REFERENCIAS BIBLIOGRÁFICAS}

Diário da República n. ${ }^{\circ} 205$, Portaria n. ${ }^{\circ} 1068,4$ de setembro de 2001, I - Série - B.

Diário da República n. ${ }^{\circ} 60$, Decreto-lei n. ${ }^{\circ} 74,24$ de março de 2006, Série I - A.

Caballero, A.; Manso, J.; Matarranz, M.; y Valle, J. M. (2016). Investigación en Educación Comparada: Pistas para investigadores noveles. Revista Latinoamericana de Educación Comparada, 9, 39-56.

García Garrido, J. L. (1990). Fundamentos de Educación Comparada. Madrid: Dykinson.

Ferrer, F. (2002). La educación comparada actual. Barcelona: Ariel.

Leitão, A.P. (2013). A Educaçao Social em Portugal: O início de um percurso. Praxis Educare, 1, 19-22.

Martínez Usarralde, M. J. (2003). Educación comparada. Nuevos retos, renovados desafíos. Madrid: La Muralla.

Martínez Usarralde, M. J. (2006). La Educación Comparada revisitada: Revisión a la evolución epistemológica y temática de la era postcomparada. Tendencias pedagógicas, 11, 77-100.

Rocha, P. y Camacho, G. (2009). A Avaliaçao da Concretiçao do Processo de Bolonia numa Instituçao de Ensino Superior Portuguesa, REEC, Revista Española de Educación Comparada, 15, 41-59.

Senent, J. M. (n.d.). Recursos metodológicos básicos en la comparación socioeducativa. Dossier de clase. Valencia: Documento no publicado.

Senent, J. M. (1994). Los educadores sociales en Europa. Modelos formativos francófonos y meridionales. Valencia: Universidad de Valencia.

Senent, J. M. (2011). Educación social: la diversidad como eje de trabajo en clave internacional. RES, Revista de Educación Social, 13.

Teixeira, L. (2014). Aprendizagem profissional e transições para o mundo do trabalho. Pistas para refletir sobre a formação dos educadores sociais. Interacçoes, 29, 238-255.

Timóteo, I. (2013). A evolução da Educação Social: perspectivas e desafios contemporáneos. Praxis Educare, 1, $12-18$. 